O médico é aquele que detém a maior responsabilidade da "cura" e, portanto, o que tem o maior sentimento de fracasso perante a morte do enfermo sob os seus cuidados. Contudo, nós, médicos, devemos ter em mente que o entusiasmo por uma possibilidade técnica não nos pode impedir de aceitar a morte de um doente. E devemos ter maturidade suficiente para pesar qual modalidade de tratamento será a mais adequada. Deveremos, ainda, considerar a eficácia do tratamento pretendido, seus riscos em potencial e as preferências do enfermo e/ou de seu representante legal.

Diante dessas afirmações, torna-se importante que a sociedade tome conhecimento de que certas decisões terapêuticas poderão apenas prolongar o sofrimento do ser humano até o momento de sua morte, sendo imprescindível que médicos, enfermos e familiares, que possuem diferentes interpretações e percepções morais de uma mesma situação, venham a debater sobre a terminalidade humana e sobre o processo do morrer.

Torna-se vital que o médico reconheça a importância da necessidade da mudança do enfoque terapêutico diante de um enfermo portador de doença em fase terminal, para o qual a Organização Mundial da Saúde preconiza que sejam adotados os cuidados paliativos, ou seja, uma abordagem voltada para a qualidade de vida tanto dos pacientes quanto de seus familiares frente a problemas associados a doenças que põem em risco a vida. A atuação busca a prevenção e o alívio do sofrimento, através do reconhecimento precoce, de uma avaliação precisa e criteriosa e do tratamento da dor e de outros sintomas, sejam de natureza física, psicossocial ou espiritual.

\title{
Direito à Vida — O Princípio da Proporcionalidade
}

\author{
RIGHT TO LIFE - THE PRINCIPLE OF THE PROPORTIONALITY
}

Felippe Mendonça ${ }^{(*)}$

Em 28 de novembro de 2006, com vigência a partir de sua publicação, o CFM editou Resolução Normativa permitindo aos médicos brasileiros a prática de ortotanásia, procedimento onde o médico limita ou suspende tratamentos que prolonguem a vida de doente em fase terminal, de enfermidade grave e incurável, garantindo-Ihe os cuidados necessários para aliviar

$\left({ }^{\star}\right)$ Advogado, Presidente da Comissão de Defesa da República e da Democracia da Ordem dos Advogados do Brasil, secção São Paulo, subsecção Santo Amaro. E-mail: <advfmend @ gmail.com>. 
os sintomas que levam ao sofrimento, respeitando a vontade do paciente ou de seu representante legal. ${ }^{(1)}$

Para analisarmos a constitucionalidade de tal ato normativo, primeiramente, devemos analisar as diferenças entre eutanásia, ortotanásia e distanásia. Segundo os próprios conceitos médicos, eutanásia é o procedimento onde se abrevia a vida do enfermo incurável, sem dor ou sofrimento, enquanto que a ortotanásia respeita o momento natural de sua morte, sem prolongar a vida, e a distanásia, extremo oposto, prolonga a vida do paciente o máximo possivel, impedindo sua morte ${ }^{(2)}$.

Dentro das especificações, criando uma linha extremamente tênue de diferenciação, se divide a eutanásia em ativa e passiva, sendo a primeira a prática de qualquer ato eficaz ao óbito do paciente, enquanto a segunda, eutanásia passiva, a que cessa todos e quaisquer procedimentos, levando o enfermo ao óbito em uma questão de tempo.

Fica evidente uma proximidade muito grande entre a eutanásia passiva e a ortotanásia, onde, em tese, a segunda seria praticada no exato momento natural da morte do doente, enquanto que a primeira não levaria isso em conta, menosprezando-se as possibilidades médicas e esperando a morte daquele que desistiu de viver, ou desistiram por ele, caso seja uma permissão do responsável.

Valoradas as diferenças, percebe-se que a Resolução Normativa do CFM leva em conta um preciosismo sobrenatural do profissional para que ele pratique uma ortotanásia e não uma eutanásia passiva, pois a diferença tênue entre elas é, supostamente, percebida apenas por este, que sabe exatamente o momento da morte natural de seu paciente.

Esclarecidas as questões etimológicas, inicia-se a análise da constitucionalidade do ato normativo editado pelo CFM, onde, por etapas, analisamse primeiro os valores envolvidos, quais sejam, os princípios da dignidade humana e o da inviolabilidade do direito à vida, para, posteriormente, concluir pela constitucionalidade ou não da norma e outros aspectos relevantes.

Para existência de uma inconstitucionalidade, são necessários dois pressupostos: a existência de um ato legislativo e uma superioridade hierárquica da Constituição Federa|(3).

Quando o Conselho Federal de Medicina edita uma Resolução, tarefa que lhe é atribuída pela Lei n. 3.268/57, alterada pela Lei $n$. 11.000/04 e regulamentada pelo Decreto n. 44.045/58, está, necessariamente, agindo de forma legislativa, existindo, portanto, um ato legislativo. Nosso ordena-

\footnotetext{
(1) Redação da Resolução Normativa n. 1.805/2006.

(2) WIKIPEDIA, enciclopédia virtual. Disponivel em <www.wikipedia.org>.

(3) TAVARES, André Ramos. Curso de direito constitucional. 2. ed. rev. e ampl. São Paulo: Saraiva, 2003. p.175.
} 
mento jurídico pressupõe a hierarquia das normas, com a superioridade hierárquica da Constituição, seguindo a pirâmide Kelsiana.

A dignidade da pessoa humana garantida na Carta Magna no art. $1^{\circ}, \mathrm{III}$, princípio basilar em nosso ordenamento jurídico, é de extrema subjetividade, mantendo apenas sua existência, sem nenhum parâmetro técnico adotado para que se elucidem suas limitações. Contrário não poderia ser, tendo em vista evoluções das sociedades que geram alterações em parâmetros: o que hoje pode ser considerado digno, amanhã pode ser indigno.

A princípio, dignidade à pessoa humana é sinônimo de respeito. Respeito a sua vida, a seus costumes, a sua honra etc. Maria Garcia, em seus estudos, baseia-se no dicionário Aurélio para corresponder à dignidade à autoridade moral, respeitabilidade, respeito a si mesmo, onde o dicionário estende-se, dando equivalência à importância do brio, da honestidade, da decência, dentre outras. Maria Garcia ainda busca a origem da palavra, encontrando-a em latim como dignitas, com significado de virtude, honra e consideração(4).

O ser humano, naturalmente sociável, encontra sua dignidade dentro dos limites da sociedade em que vive. Sua dignidade é o respeito a sua pessoa, dentro de suas individualidades. Respeito aos costumes, integridade física, religião, moral e honra, dentre outros. Entretanto, toda dignidade deriva da sociedade, não podendo, por mais que o indivíduo entenda como digno, extrapolar os limites da mesma. De forma exemplificativa, de nada adianta um membro da sociedade brasileira alegar seus costumes provindos do Oriente Médio para lavar sua honra e matar o amante de sua esposa. O impedimento de sua conduta não fere sua dignidade, pois esta deriva, necessariamente, da sociedade em que vive.

De forma conclusiva, a dignidade da pessoa humana trazida pelo texto constitucional equivale ao respeito necessário a todo ser humano, dentro dos limites impostos pela sociedade. Sendo digno aquele que se comporta dentro dos parâmetros impostos, tornando-se cíclica, pois os parâmetros devem respeitar, na medida máxima possivel, a individualidade da pessoa humana.

Resta valorar a inviolabilidade do direito à vida. A Constituição Federal de 1988 nos traz não apenas o direito à vida, mas também uma inviolabilidade do mesmo, no caput do art. 5ํ, apogeu dos direitos e garantias individuais. Atribui-se a Ulysses Guimarães uma suposta resposta dada quando questionado porque os direitos e garantias individuais, tão importantes na chamada Constituição Cidadã, só estavam expressos no $5^{\circ}$ artigo, por que não no primeiro? Em resposta, a frase: "A ditadura nos deu o Al 5. Eu Ihes devolvo o art. 5"”

(4) GARCIA, Maria. Limites da ciência: a dignidade da pessoa humana: a ética da responsabilidade. São Paulo: Ed. Revista dos Tribunais, 2004. p. 196. 
Sendo verdade ou não, a questão pertinente é a importância dada a este artigo, que levou gerações às ruas que lutaram por direitos que antes Ihes eram negados. Grande parte do espírito da nossa Lei Maior encontrase implícito neste artigo, sendo o respeito supremo à vida, não um direito, mas um direito inviolável.

Para André Ramos Tavares, o direito à vida é o mais básico de todos, sendo pré-requisito para todos os demais direitos, considerando-o o mais sagrado dentre os direitos humanos ${ }^{(5)}$. André ainda segue explicando ser o direito à vida, em princípio, o direito a permanecer vivo e, em um segundo aspecto, o direito de viver de forma compativel à dignidade humana, ou seja, ter direito à alimentação, moradia, vestuário, saúde, educação, cultura e lazer(6).

Contrário à forma taxativa do que seria a dignidade humana inclusa no direito à vida, acrescentamos outros parâmetros de dignidade, como segurança e liberdade do cidadão honesto; entretanto, enfatizamos que são essas as condições mínimas de dignidade referentes ao direito à vida, não podendo variar de acordo com a sociedade, como a forma mais ampla do direito à dignidade da pessoa humana, imposto pelo inciso III do art. 10 como fundamento da República Federativa do Brasil.

Uma importante observação referente ao direito à saúde, derivado do direito à vida e da dignidade da pessoa humana, o art. 196 da Constituição Federal, nos remete à obrigatoriedade do Estado em prover pela saúde de todos, com o esforço máximo possível para que seja mantida a vida.

A concepção do que é a vida varia no momento em que ela se inicia: se na formação do embrião, durante a fase fetal ou no nascimento; mas, não é variável no seu término: a morte cerebral, conceito adotado e pacífico para viabilizar a doação de órgãos.

Resta traçar os paralelos: a vida é um direito inviolável; a dignidade da pessoa humana é sinônima de respeito à mesma e se corresponde diretamente com a sociedade; o direito à saúde deriva de ambos; a ortotanásia se aproxima da eutanásia passiva e cessa o tratamento médico, aguardando o momento da morte natural.

Voltando, portanto, ao cerne da questão, a Resolução do CFM permite ao médico, profissional responsável, a prática da ortotanásia, sendo respeitada a vontade do paciente ou de seu responsável. No momento em que está sendo submetido a um tratamento clínico, o paciente já pode encontrar-se em um estado mental debilitado, não sendo mais capaz de discernir o que é certo ou errado. Pior, pode estar desacordado e ser seu representante legal aquele que vai decidir por sua desistência. Ao médico cabe a

(5) TAVARES, André Ramos. op. cit., p. 399.

(6) Id., loc. cit. 
estupenda capacidade técnica de verificar o exato momento em que o paciente morreria naturalmente, não podendo cessar o tratamento antes deste período, sob pena de incorrer em eutanásia passiva.

De fato, parece mais digno, para aquele que sofre com um tratamento ineficaz, cessar os procedimentos médicos que Ihe mantenham vivo; entretanto, é extremamente subjetivo afirmar se é ou não ineficaz o tratamento, se não existe mais nenhuma perspectiva de vida, ou se seu sofrimento é realmente degradante.

Religiões se disseminaram pelo mundo prometendo curas milagrosas, apoiando-se exatamente sobre casos de pessoas sem perspectiva de vida que, repentinamente, se curaram. Não raro, vê-se no noticiário, a história de um enfermo que saiu do estado de coma após anos e existem inúmeros relatos de pessoas que milagrosamente tiveram um câncer curado, quando já estavam desenganadas pelos médicos. O fato é que persiste a máxima: "enquanto há vida, há esperança".

Seguindo de forma mais técnica, devemos buscar a proporcionalidade. Para averiguar a constitucionalidade de uma lei, é necessário captar não só os valores normativos, como também os fatos reais, efeitos do ato normativo, e verificar se estes são constitucionais. A forma utilizada para valorar é a proporcionalidade ${ }^{(7)}$.

No controle da constitucionalidade, o princípio da proporcionalidade é o instrumento apto para soluções de conflitos entre outros princípios ${ }^{(8)}$, quando, no caso concreto, um deve sobrepor-se ao outro e a decisão deverá utilizar-se da proporcionalidade para evitar a injustiça, tomando um por "superior" ao outro, valorando-o em detrimento daquele que, aparentemente, se utilizado, causará um prejuizo maior à população e uma afronta mais gravosa à constituição.

Analisando sobre o prisma da proporcionalidade, devemos então nos questionar: é proporcional permitir que, baseando-se na dignidade de alguns, todos corram o risco de serem submetidos à ortotanásia, podendo, nem ao menos, serem capazes de autorizar o procedimento? O que é mais importante, o direito à vida de todos os seres humanos ou a dignidade daquele que perde a esperança? É proporcional correr o risco de, por equivoco médico, pessoa ainda curável ser submetida à ortotanásia e falecer? Existe um grau de certeza absoluta para a ineficácia de tratamentos médicos? É proporcional ao princípio da dignidade da pessoa humana exigirmos a suprema capacidade técnica do médico em determinar exatamente o momento da morte natural para não incorrer em conduta tipificada criminalmente? Pois, aquele que por negligência, imprudência ou imperícia

(7) Id. Ibid., p. 178-180. No mesmo sentido, MENDES, Gilmar Ferreira. Direitos fundamentais e controle de constitucionalidade: estudos de direito constitucional. São Paulo: Celso Bastos; Instituto de Direito Constitucional, 1998. p. 466.

(8) TAVARES, André Ramos. op. cit., p. 536. 
errar o momento exato e cessar o tratamento antes da fatídica hora da morte, deverá ser processado, julgado e, ao final, condenado por homicídio. Culposo, neste caso, se admitida a Resolução Normativa em nosso ordenamento jurídico.

Portanto, não parece proporcional permitir a ortotanásia baseando-se na dignidade da pessoa humana, em detrimento da inviolabilidade do direito à vida. Nem ao menos é aconselhável ao médico, mesmo aos que apóiam a prática, agir sob tal conduta, pois um filho inconformado com a morte do pai poderá, em tese, questionar sua capacidade de discernimento, tendo em vista medicamentos tomados e buscar pela justiça para que o médico sofra as sanções previstas em lei, inclusive indenizatórias.

Outra possibilidade, depois de assumida a prática e cessados os tratamentos médicos, se o paciente sobreviver um periodo de tempo superior ao do efeito do medicamento, configurará inequivocamente a eutanásia passiva.

Pela proporcionalidade, melhor valorar o princípio da inviolabilidade do direito à vida em detrimento do princípio da dignidade da pessoa humana, aplicando o primeiro em sua plenitude e desatendendo o outro o mínimo possivel(9).

Seguindo os passos traçados, valorados os direitos fundamentais envolvidos, feito o juízo da proporcionalidade entre a norma em questão e os direitos fundamentais, resta analisar se a Resolução Normativa 1.805 de 2006 do CFM pode ser considerada inconstitucional ou não.

Elival da Silva Ramos caracteriza a inconstitucionalidade como uma relação de desconformidade do ato legislativo com a Constituição, enquanto o primeiro é o objeto; a segunda, o parâmetro(10). André Ramos Tavares conclui que a inconstitucionalidade é um fenômeno atrelado à superioridade hierárquica da Constituição (estrutura hierárquica do sistema jurídico). Quando uma lei infraconstitucional não se curva aos padrões adotados, previamente estabelecidos pela Lei Maior, violando-os no aspecto formal ou material. Os efeitos dessa violação também são regulados pelo sistema. Afirmando, por fim, que os efeitos práticos da delimitação da inconstitucionalidade são extremamente graves e não apenas acadêmicos ou científicos ${ }^{(11)}$.

Entretanto, para um ato normativo ser considerado inconstitucional ele deve violar diretamente a Constituição, caso contrário, trata-se de uma ilegalidade e uma inconstitucionalidade indireta. Sendo assim, quando se ataca um ato normativo que afronta uma lei infraconstitucional e, automaticamente, a própria Constituição, chamá-lo de inconstitucional é uma forma

(9) Conforme ensinamento de GUERRA FILHO, Willis Santiago. Processo constitucional e direitos fundamentais. São Paulo: Instituto Brasileiro de Direito Constitucional; Celso Bastos, 1999. p. 536. (10) RAMOS, Elival da Silva. A inconstitucionalidade das Leis: vicio e sanção. São Paulo: Saraiva, 1994. p. 62; TAVARES, André Ramos. op. cit., p. 175.

(11) TAVARES, André Ramos. op. cit., p. 177. 
mais ampla do conceito pois, academicamente, no sentido mais estrito do termo, o correto é tratá-lo como uma ilegalidade(12).

O ato normativo objeto de análise pode ser considerado ilegal por afrontar diretamente o Código Penal e, se este for o conceito escolhido, apenas no sentido amplo do termo é que poderá ser chamado de inconstitucional.

Por outro lado, tratando como ato aparentemente interposto, fica possível atacá-lo como inconstitucional no sentido estrito, pois o Código Penal não exemplifica a ortotanásia como crime, sendo a conduta tipificada como homicídio pelo art. 121, enquanto que a Constituição, expressamente, garante a inviolabilidade do direito à vida e o direito à saúde, permitindo, desta forma, que normas infraconstitucionais apenas ampliem o direito à vida, nunca que o debilite.

Ato aparentemente interposto ocorre quando o ato normativo analisado afronta diretamente tanto uma norma infraconstitucional como a própria Constituição, permitindo que o trate não apenas como ilegal como também como inconstitucional. Jorge Miranda - um dos doutrinadores que acreditam que mesmo quando um ato normativo ataca diretamente a Constituição, mas antes viola uma lei infraconstitucional, não se deve ser tratado como inconstitucional - admite que caso seja uma ofensa à norma constitucional, de fundo, de competência ou de forma, a denominação é possivel(13).

O caput do art. $5^{\circ}$ nos traz uma inviolabilidade do direito à vida e não somente o próprio. Assim sendo, prescreve que uma lei infraconstitucional não poderá debilitá-lo jamais, sendo portanto a Constituição a única competente para tanto. Com isso temos que um ato normativo que transgrida 0 contido no caput do art. $5^{\circ}$ e debilite o direito à vida contém um vício material, por ser a vida matéria constitucional.

O conceito adotado aqui defendido é que se trata de uma inconstitucionalidade, no sentido estrito, direta e material, restando saber se o ato normativo deve ser objeto em Ação Direta de Inconstitucionalidade (ADIn) ou de uma Argüição de Descumprimento de Preceito Fundamental (ADPF). Segundo o caput do art. $1^{\circ}$ da Lei n. 9.882/99, esta última será utilizada para evitar ou reparar lesão a preceito fundamental resultante de ato do Poder Público.

Primeiramente cumpre ressaltar brevemente, por ser matéria ampla condizente de um estudo próprio, ser o posicionamento aqui adotado de que a limitação para atos do Poder Público trazida pela Lei da Argüição, em princípio, também incorre em inconstitucionalidade, pois o texto constitucional oferece a garantia de que todo o descumprimento a preceito fundamental será

(12) No mesmo sentido, TAVARES, André Ramos. op. cit., p.182-184; Elival da Silva Ramos, A Inconstitucionalidade das Leis, p. 64; Marcelo Neves, Teoria da Inconstitucionalidade das Leis, p. 72 e 73 e MIRANDA, Jorge. Manual de direito constitucional. 2. ed. rev. Coimbra: Coimbra Ed., 1988. t. 2, p.276.

(13) MIRANDA, Jorge. op. cit., t. 2, p. 278; e TAVARES, André Ramos. op. cit., p. 184. 
protegido por essa via e não apenas os provindos de atos do Poder Público. Entretanto, esse ainda não é o entendimento do Supremo Tribunal Federal.

Mesmo admitindo que apenas atos do Poder Público possam ser objeto em ADPF, quando uma entidade de classe legisla, ela atua na esfera do poder público, equivalendo-se por ser uma autarquia, integrante da administração indireta.

Outra aparente inconstitucionalidade na referida Lei da Argüição encontra-se na determinação da subsidiariedade trazida pelo art. $4^{\circ}$, $\S 1^{\circ}$, por não existir uma hierarquia entre a ADIn e a ADPF, sendo as duas garantias trazidas pelo texto constitucional. Mas, admitindo-a, é possivel sanar a inconstitucionalidade de Resolução Normativa pela via da ADIn considerando-se, assim como aqui defendido, tratar-se de uma inconstitucionalidade direta, pois, tratando-a como indireta, só é possível sanar pela via da ADPF.

Em consonância com o defendido por André Ramos Tavares, as duas garantias têm campos próprios de atuação, devendo uma evitar ou reparar lesões causadas por leis ou atos normativos dentro do campo não fundamental e outra, evitar ou reparar lesões causadas por qualquer ato, normativo ou não, dentro do campo dos direitos fundamentais ${ }^{(14)}$.

A própria separação entre atos normativos ou não normativos, onde uma se restringe e a outra não, fortalece a tese de que ambas devem coexistir no ordenamento, atuando cada uma em seu campo específico, por ser a defesa dos preceitos fundamentais extremamente valorada pela Carta Magna.

De forma conclusiva, a Resolução Normativa n. 1.805/06 do Conselho Federal de Medicina é inconstitucional, tratando-se de uma inconstitucionalidade no sentido estrito, direta e material, que deve ser objeto futuro de uma Argüição de Descumprimento de Preceitos Fundamentais, a ser proposta pelos legitimados. E a atuação de médicos em atenção ao seu conteúdo encontra-se tipificada pelo Código Penal no art. 121, como homicídio, enquanto perdurar a vigência da Resolução e seus efeitos ${ }^{(15)}$.

\section{REFERÊNCIAS}

FERREIRA, Aurélio Buarque de Holanda. Novo Dicionário da Lingua Portuguesa. 2. ed. rev. e aum. 5. impressão. Rio de Janeiro: Nova Fronteira. 1986.

(14) TAVARES, André Ramos. op. cit., Capitulo XV: Da Argüição de Descumprimento de Preceito Fundamental, p. 262-271.

(15) Entendimento já explanado em nota da Ordem dos Advogados do Brasil em conjunto com o Ministério Público Federal. 
GARCIA, Maria. Limites da ciência: a dignidade da pessoa humana: a ética da responsabilidade. São Paulo: Ed. Revista dos Tribunais, 2004.

GUERRA FILHO, Willis Santiago. Processo constitucional e direitos fundamentais. São Paulo: Instituto Brasileiro de Direito Constitucional; Celso Bastos, 1999.

KELSEN, Hans, 1881-1973. Teoria geral das normas. Tradução de José Florentino Duarte. Porto Alegre: Fabris, 1986.

MENDES, Gilmar Ferreira. Direitos fundamentais e controle de constitucionalidade: estudos de direito constitucional. São Paulo: Celso Bastos; Instituto de Direito Constitucional, 1998.

MIRANDA, Jorge. Manual de direito constitucional. 2. ed. rev. Coimbra: Coimbra Ed., 1988. t. 2.

NEVES, Marcelo. Teoria da Inconstitucionalidade das Leis. São Paulo: Saraiva, 1988.

RAMOS, Elival da Silva. A inconstitucionalidade das Leis: vício e sanção. São Paulo: Saraiva, 1994.

TAVARES, André Ramos: Curso de direito constitucional. 2. ed. rev. e ampl. São Paulo: Saraiva, 2003.

WIKIPEDIA, enciclopédia virtual. Disponível em <www.wikipedia.org>.

\title{
FundamentaÇão JuRídica da ResoluÇão N. 1.805/2006
}

\section{JURIDICAL BASIS FOR RESOLUTION N. 1.805/2006}

\author{
Livia Haygert Pithan (*) \\ Gustavo Silveira Borges ${ }^{(\star \star)}$
}

\section{INTRODUÇÃO}

O Conselho Federal de Medicina (CFM), no dia 28 de novembro de 2006, publicou uma polêmica resolução, aprovada por unanimidade, que permite aos médicos brasileiros suspender tratamentos e procedimentos

(*) Professora de Bioética e Direito da Pontifícia Universidade Católica do Rio Grande do Sul (PUCRS), mestre em Direito e doutoranda em Direito Privado na Universidade Federal do Rio Grande do Sul (UFRGS). E-mail: <liviahp@terra.com.br>.

("*) Advogado, especialista em Ciências Penais pela PUC-RS e mestrando em Ciências Criminais na PUC-RS. E-mail: <gustavoborges @ hotmail.com>. 